\title{
Introducción a las huellas de uso: los resultados de la experimentación
}

Carmen Gutiérrez Sázz

HISTORIA DE LA INVESTIGACIÓN

El uso dado al utillaje lítico prehistórico ha despertado el interés de numerosos especialistas desde la conformación de la arqueología prehistórica en el siglo xIX. Podemos distinguir, en términos generales, cuatro líneas de investigación en el tema de la funcionalidad.

\section{SIN OBSERVACIÓN DE HUELLAS}

\section{Sin experimentación}

Semejanza morfológica: esta primera línea se inicia por la necesidad de adoptar una terminología apropiada para los objetos reciente-

Este trabajo es un resumen de la Tesis Doctoral de la autora que con el titulo "Huellas de uso: pautas de análisis experimental". fue leída el 14 de marzo de 1990 en la Facultad de Geografía e Historia de la Universidad Nacional de Educación a Distancia de Madrid. Actuaron de tribunal calificador los doctores don E. Ripoll Perelló, don J. González Echegaray, don M. Hoyos Gómez, don J. González Tresguerres y doña V. Cabrera Valdés. Quiero agradecer aqui a los miembros del Departamento de Prehistoria e Historia Antigua y de la Secretaría de dicha Facultad de la UNED las facilidades prestadas para la iramitación de la lectura de la Tesis y, muy especialmente, a los doctores doña $V$. Cabrera Valdés y don $F$. Bernaldo de Quiros, Director del trabajo, la ayuda y el apoyo que nos han brindado durante su realización. 
mente descubiertos y reconocidos como prehistóricos. La denominación de los objetos se establece por la semejanza de forma, tanto con utensilios actuales - cuchillo, hacha, cincel o perforador- (Boucher de Perthes 1846-1865) como con instrumentos de los pueblos primitivos, a través de la Etnografia; en esta última tendencia están los estudios de Lubbock (1872) y Evans (1872) sobre los indios americanos y aborígenes australianos para la interpretación funcional de la industria preshistórica inglesa, entre otros. Se apoyan en la idea de que la semejanza morfológica equivale a la semejanza funcional.

\section{Con experimentación}

Por efectividad supuesta: se realizan experimentos de simulación de utillaje lítico que muestran la posible gama de usos de un útil. Se ha trabajado con raspadores sobre hueso (Cox, 1936), madera (Over, 1937) y piel (Ray, 1937), con buriles sobre hueso (Bordes, 1965) y con hachas pulidas enmangadas cortando árboles (Müller, 1903), comprobándose la eficacia desarrollada en estas tareas especificas. En la misma tendencia están los experimentos replicativos de actividades, dedicados generalmente al descuartizado de animales (Walker, 1978, y Newcomer, 1980, entre varios más). Son réplicas intuitivas de las funciones ejercidas, a los experimentos no les sigue una observación de las huellas dejadas durante el trabajo ni un análisis que categorice dichas huellas y pueda ser aplicado al material arqueológico.

CON OBSERVACIÓN DE HUELLAS

\section{Sin experimentación}

Por apreciaciones tipológicas: esta tendencia es la primera que toma en consideración las huellas o marcas apreciadas sobre los filos de las piezas, atribuyéndolas al uso. En este grupo están los estudios de raspadores de Rosenfeld (1970), Bordes (1973) y Brezillon (1973), así como los de denticulados, muescas y raclettes de Kantman (1970), y los de buriles de Seitzer, Lenoir y Pradel en 1973. No se observan las posibles huelias de uso de la industria lítica en su conjunto, sino que se 
refieren a categorias o grupos tipológicos determinados, error asimilado del valor que se ha concedido en exclusiva a la tipologia en los conjuntos industriales.

Por contexto arqueológico: en este caso se situa el análisis de algunas piezas cuyo estado de conservación es excepcional, tales como puntas de flecha enmangadas en su astil de asta o madera de yacimientos mesolíticos báiticos. En otras ocasiones la deducción se ha establecido a partir de la asociación de conjuntos liticos a otros restos arqueológicos, como la presencia de piezas con desperfectos juntos a huesos descarnados (Hammat, 1970) o en niveles relacionados con arte rupestre (Prat y Sonneville-Bordes, 1969; Moure Romanillo y González Morales, 1988).

En ambos casos y a pesar de su valor, en cuanto que se parte de la observación de los filos supuestamente activos, se trata de una observación parcial puesto que es únicamente macroscópica, centrada en las roturas del borde o desconchados y el redondeamiento y su posición en la pieza. Por otra parte, al no contrastar sus resultados con la experimentación dudosamente se pueden atribuir las huellas a funciones concretas o considerar que su formación se deba al uso o a causas ajenas como la talla o a procesos de sedimentación.

\section{Con experimentación}

La formación de una metodologia que une experimentación con observación se inicia con prontitud pero su aplicación es relativamente reciente. Los primeros antecedentes se deben a la controversia suscitada por la cuestión del lustre de cereal iniciada por Spurrel (1892), y más adelante a las reflexiones de Sonnenfeld (1962) acerca de la escasa validez de los experimentos a los que no seguia una observación detenida de las huellas aparecidas.

Hasta la década de los sesenta el problema de la funcionalidad ha tenido un tratamiento parcial que ha sido incapaz de generar una disciplina técnica rigurosa, tan necesaria para la ampliación de nuestros conocimientos sobre las formas de vida antiguas. El principal resurgimiento del tema se produjo a partir de la publicación al inglés en 1964 del libro de Semenov Lithic Technology. En él se recogian las investigaciones sobre funcionalidad realizadas desde 1934 por Semenov y sus colegas de la Academia de Ciencias de Leningrado. Su análisis de las industrias líticas y óseas prehistóricas se apoya en la observación microscópica de las numerosas piezas experimentales trabajadas. 
La aparición del libro de Semenov donde se ofrecen algunos avances importantes acerca de la funcionalidad del utillaje prehistórico, en una época en que se está gestando la llamada "Nueva Arqueología", contribuyó a sentar las bases de la actual traceología o estudios de huellas de uso.

Contradictoriamente el buen recibimiento inicial a la obra de Semenov se fue transformando en escepticismo a medida de que los investigadores occidentales se veian incapaces de llegar a las conclusiones realizadas por el equipo soviético. En primer lugar, la falta de similitud de los equipos ópticos de Occidente y los utilizados por Semenov y sus colegas. En segundo término, la ausencia en las industrias líticas de las famosas estrías, huellas indicadoras del movimiento del útil durante el trabajo y tan abundantes en las colecciones soviéticas, según se aprecia en las fotografias publicadas, debido en parte al factor anterior. Pero el motivo principal radica en la escasa sistematización que se hace de las huellas y los factores que las provocan. El libro es el resultado de varios años de investigaciones a menudo parciales, su objetivo era no tanto presentar rigurosamente un método de análisis como ofrecer los logros obtenidos.

Es en 1974 cuando se publican en Occidente las primeras investigaciones sistemáticas apoyadas en la experimentación, debidas a Tringham y su equipo, en la Universidad de Harvard y a Keeley en la de Oxford. Ambos inician dos corrientes traceológicas diferenciadas por el equipo óptico empleado: lupa binocular los primeros y microscopio metalográfico el segundo, que crean las denominadas Escuelas de altos y bajos aumentos.

La lupa binocular se empleaba normalmente con menos de $80 \mathrm{X}$, las huellas observadas eran los desconchados y el embotamiento del borde. A través de la sistematización de su morfología, cantidad y posición se infería el movimiento realizado y la dureza relativa de la materia trabajada.

El microscopio metalográfico, al que pronto se sumó el electrónico de barrido, alcanza aumentos mayores, aunque su uso más frecuente es en torno a $200 \mathrm{X}$. Con él se realiza un reconocimiento más preciso de la superficie del borde activo, lo que permite la observación de dos huellas de uso más: el pulimento o alteración característica en la microtopografía del útil, relacionada con la materia trabajada, y las estrías o rasgos lineales que revelan la posición del borde en el movimiento. Para Keeley la identificación de la materia trabajada y el movimiento empleado radica en 
la correcta interpretación de los cuatro tipos de huellas, aunque concede más importancia al pulimento y a las estrias.

Enseguida se produjo el debate entre los seguidores de ambas escuelas. Éste se centra principalmente en la validez de los desconchados como huella diagóstica de uso. Mientras que para los seguidores de los bajos aumentos las características de esta huella permiten realizar una identificación correcta del uso, para los de altos aumentos los desconchados ofrecen un comportamiento en exceso vago y general; las conclusiones deducidas de su análisis únicamente pudieran tener valor para matizar las obtenidas por el resto de las huellas, especialmente del pulimento, pero nunca como únicos indicadores de uso. En la traceología actual la mayor parte de analistas han adoptado el método de altos aumentos, a pesar de las numerosas controversias que se siguen suscitando incluso hoy día.

\section{Los tests ciegos}

La capacidad de la técnica de altos aumentos de diagnosticar el uso dado a la industria lítica, quedó enseguida de manifiesto por el test ciego (blind-test) realizado por Keeley y Newcomer en 1975. Newcomer talló y usó sobre diversas materias una colección de 16 piezas líticas que fueron analizadas posteriormente por Keeley. De todo el conjunto identificó el borde trabajado en 14, la acción ejecutada en 12 y la materia trabajada en nueve de ellos de forma total y en dos parcialmente. Aunque estos resultados fueron calificados de muy prometedores en su dia, nuevos tests ciegos realizados con posterioridad (Unrath et alii, 1984/85/86; Newcomer et alii, 1986; Grace et alii, 1988; Grace, 1989) han recalificado el conjunto de resultados obtenidos y han hecho una llamada de atención acerca de la excesiva confianza depositada en esta técnica.

En concreto, el test ciego realizado por Newcomer con analistas del Instituto Británico de Arqueologia (1986), en el que se contrastaron las respuestas con un tratamiento de imagen por ordenador de los pulimentos, ofreció unos resultados en exceso pobres. Hay que considerar que a los analistas se les indujo a identificar el uso únicamente a partir del pulimento, sin considerar al resto de las huellas; por otra parte, algunos de los usos experimentales habian tenido una duración de escasos minutos, con lo que el pulimento difícilmente podía desarrollarse; en tercer lugar se exigió dar una única respuesta, hecho éste que constrasta con la realidad del análisis traceológico, donde se considera preferible elimi- 
nar los diagnósticos dudosos o considerar otras causas posibles. Finalmente, un test ciego con escasos aciertos no tiene porque invalidar los buenos resultados obtenidos anteriormente.

También los analistas de bajos aumentos han realizado numerosos tests ciegos de comprobación de su técnica. Entre ellos se destacan los de Odell et alii (1980) y Shea (1988). Aunque para sus participantes los resultados obtenidos han sido prometedores, la reserva que produce esta técnica obliga a calificarlos con cautela.

En conjunto, los tests ciegos no sólo han resultado ser positivos para comprobar la fiabilidad del método, sino que se han mostrado igualmente útiles para analizar las causas de los errores.

Diversificación de objetivos

La técnica propuesta por Keeley ha tenido numerosos seguidores. Además de ser aplicada a un extenso espectro de colecciones arqueológicas, se ha seguido experimentando con el objeto de conocer la respuesta de elementos no tratados por Keeley. Asi, se han ampliado tanto las materias trabajadas, con la introducción de pescado (Van Gijn, 1984/ 85/86), como las materias primas: nuevos tipos de sílex (Anderson, 1981; Mansur, 1983), además de cuarcita, basalto (Plisson, 1982) o cuarzo (Sussman, 1985), entre otros, y de actividades, entre las que destacan las de proyectil para la caza y la pesca (Moss y Newcomer, 1982; Geneste y Plisson, 1986).

Dentro del campo de la identificación se han elaborado nuevos experimentos en torno a la fiabilidad de cada tipo de huella como elemento diagnóstico, aunque ha sido el pulimento el que ha generado mayor cantidad de monografías y debates. De ellos hablaremos en la exposición de cada una de las huellas.

No han faltado tampoco los experimentos dirigidos a la formación de huellas por causas ajenas al uso, como los trabajos de talla y retoque (Keeley, 1980; Ibáñez Estévez et alii, 1987) o las debidas a procesos accidentales, tanto de sedimentación (Flenniken y Haggarty, 1979; Plisson, 1983, 1984/85/86) como de tratamiento arqueológico (Willye, 1975; Gutiérrez Sáez et alii, 1987). 


\section{EL MÉTODO EXPERIMENTAL}

La traceología toma su base en la experimentación por un doble motivo: enseñar al experimentador la comprensión de un gesto y los efectos que provoca, las huellas, y obtener una colección con la que comparar las piezas prehistóricas.

Los experimentos deben de organizarse según un programa previo cuyo objetivo sea el establecimiento de cuadros reglamentados de conocimiento de causa-efecto (Schiffer, 1976). La realización de experimentos intuitivos o apoyados en patrones de eficacia actuales o etnográficos, donde no exista una estrecha relación entre todos los componentes de la función y las huellas que provoca, difícilmente nos permitira su comparación con la diversidad del material arqueológico a tratar. El método experimental conjuga sistemáticamente los diferentes elementos que se producen en un fenómeno para observar sus consecuencias. Este hecho se realiza contrastando hipótesis mediante el control de los elementos implicados o variables. Las variables son de dos tipos: las independientes o condiciones a tratar, en nuestro caso la materia prima, la materia trabajada, el tiempo, la acción ejecutada y todas las causas que concurren en la función, y las variables dependientes o efectos que se desean observar, las huellas de uso.

En un programa experimental sistemático cada experimento trata sobre una variable independiente diferente; sin embargo, un programa de estas características, siendo estricto, llegaria a ser prácticamente ilimitado $y$, por tanto, inoperante. La lógica del experimentador impone entonces los límites a funciones poco probables y conjuga los experimentos de la manera más coherente posible. Esto permite, por otra parte, la realización de pequeños experimentos puntuales para estudiar fenómenos muy concretos o experimentos replicativos con el fin de documentar condiciones específicas del material arqueológico. 
El procedimiento empleado llevaria a las siguientes etapas:

Coleccion experimental

Experimentos controlados

(formación de hipótesis)

Preparación de la muestra

Observación y registro

Análisis

(articulación de hipótesis)

Identificación

Contrastación de hipótesis

Interpretación

Experimentos puntuales
Colección arqueológica

Selección de la muestra

(formación de hipótesis)

Preparación de la muestra

Observación y registro

Análisis

(articulación de hipótesis)

Identificación

Interpretación por extrapolación

Replanteamiento

Experimentos replicativos

Contrastación

Reconstrucción arqueológica

\section{VARIABLES INDEPENDIENTES}

Son las condiciones elegidas para la experimentación, es decir, todos los elementos que incurren en la función. Las hemos dividido en dos tipos. Las "primarias" son el objetivo básico de conocimiento en la interpretación funcional, sólo tenemos constancia de ellas a través de las huellas; son la materia trabajada, la materia prima, el tiempo, los sistemas de enmangue o prensión de la pieza y la presencia de elementos aditivos como ocres. La "secundarias" nos dan información que complementa a la obtenida por las huellas y ayudan a identificar a las anteriores. Son las aportadas por el útil lítico en estudio, se trata de la materia prima, el ángulo y mofología del borde, las dimensiones y el tipo. 
Las materias primas

Los grupos prehistóricos han empleado diversas clases de roca a lo largo del tiempo y del espacio para fabricar sus utensilios, como sílex, cuarcita, cuarzo, ópalo, calcedonia, esquisto, obsidiana y basalto, entre los más comunes; en general, la mayoría pertenecen al grupo de las materias siliceas y muchas de ellas se caracterizan por su facilidad para la talla y su resistencia en el uso.

Cuando Keeley (1980) realizó sus experimentos con sílex, de textura y procedencia diversas, no observó comportamientos diferentes debidos al tipo de silex empleado. Únicamente apreció un menor desarrollo del pulimento cuando los sílex presentaban una textura más áspera, es decir, tenian grano grueso. Con posterioridad a él se ha ampliado el registro de materias primas en la experimentación. En general, los analistas coinciden en que todas las rocas experimentadas reflejan las huellas, principalmente el pulimento, observadas por Keeley en sus trabajos. Las variaciones encontradas no son cualitativas sino cuantitativas, afectan al grado de desarrollo de las huellas y se han achacado a la diferente granulometria de las materia, de forma que, "grosso modo", a una superficie de grano más gueso le corresponde menor desarrollo de pulimento, con la misma materia trabajada e idéntica duración del trabajo.

Sin embargo, durante la experimentación observamos que en los tipos de silex trabajados por nosotros existian fuertes diferencias en et desarrollo de las huellas, principalmente del pulimento, y que estos caminos cuantitativos expresaban cambios cualitativos importantes que no siempre podian atribuirse a la diferencia de granulometría.

Empezamos primero por definir el silex y encontramos que, desde el punto de vista de la Petrología, no se trata de una roca homogénea con características marcadas, sino que se incluye en el amplio grupo de las rocas siliceas sedimentarias, junto con xilópalos, radiolaritas, calcedonias y varias más, de origen, composición y estructura diversos. Las rocas siliceas sedimentarias están compuestas por más de un $50 \%$ de minerales de silice y se forman en ambiente sedimentario. Los minerales de la silice son el cuarzo a, que es la forma más pura de $\mathrm{SiO}_{2}$, el ópalo $A$, o silice amorfa (no cristalina); el ópalo CT, compuesto por cristobalita y tridimita, y el ópalo $C$, formado por cristobalita bien ordenada. Se clasifican por su origen en rocas siliceas orgánicas, cuando se forman a partir de organismos siliceos; inorgánicas, generadas bien por precipitación directa de la sílice, por reemplazamiento de otra roca o por transformación 
del mineral preexistente, y mixtas. cuando la sílice que proviene de organismos vivos se disuelve y reemplaza toda roca (Bustillo, 1983).

Aunque siempre se ha considerado que el silex es una variedad criptocristalina del cuarzo, esto es, formado por cristales de cuarzo no individualizables, el silex es una roca compuesta por tetraedros de silice que aparecen en forma de mosaicos micro y criptocristalinos, a menudo junto con megacuarzos, formas fibrosas de calcedonita y quartzina, reticulos opalinos y silice amorfa cuando se observa microscópicamente en lámina delgada.

Dado que el sílex se presentaba como una roca carente de homogeneidad optamos por caracterizar los tipos empleados en la experimentación. en un intento de explicar la diferente respuesta que habian manifestado ante el uso. Se seleccionaron muestras de 10 tipos de silex utilizados y se realizaron dos clases de análisis, uno químico, de roca total, y otro petrológico, de lámina delgada. Éstas son, en resumen, las caracteristicas principales: proporción de oxidos de silice y de calcio, elementos más importantes de la composición interna y tamaño del mosaico o cristal.

\begin{tabular}{|c|c|c|c|c|}
\hline & $\begin{array}{l}S i O \\
n_{0}\end{array}$ & $\mathrm{CaO}_{0}$ & Composicion & Mosaico \\
\hline$C 1$ & 95.98 & 0.61 & $\begin{array}{l}\text { Terrigenos de cuarzo } \\
\text { Reticulos opalinos }\end{array}$ & Criptocristalino \\
\hline$K 1$ & 94.04 & 1.89 & Romboedros de calcita & Microcristalino \\
\hline$K 2$ & 89.34 & 4,62 & Romboedros de calcita & Microcristalino \\
\hline M1 & 98.34 & & $\begin{array}{l}\text { Estructuras fibrosas } \\
\text { Megacuarzos } \\
\text { Reticulos opalinos }\end{array}$ & Criptocristalino \\
\hline$M 2$ & 94.75 & 0.21 & $\begin{array}{l}\text { Estructuras fibrosas } \\
\text { Megacuarzos }\end{array}$ & Criptocristalino \\
\hline M3 & 97.89 & & Estructuras fibrosas & Microcristalino \\
\hline M4 & 97,99 & & Estructuras fibrosas & Micro/criptocristalino \\
\hline$V_{1}$ & 92,50 & 1.94 & $\begin{array}{l}\text { Terrigenos de cuarzo } \\
\text { Estructuras fibrosas } \\
\text { Reticulos opalinos }\end{array}$ & Micro criptocristalino \\
\hline V2 & 94,21 & 1,68 & Estructuras fibrosas & Micro/criptocristalino \\
\hline$\sqrt{3}$ & 95,06 & 1,31 & Estructuras fibrosas & Micro/criptocristalino \\
\hline
\end{tabular}

Las muestras son: C1 (Maruca, Cantabria, negro de grano fino), $\mathrm{K} 1$ y K2 (Kurtzia, Vizcaya, gris oscuro de grano fino y gris oscuro con bandas calizas de grano más grueso), M1, M2, M3 y M4 (Manzanares, Madrid, marrón grano fino, gris grano medio, gris grano fino y textura semiporosa. gris grano fino y textura porosa), V1, V2 y V3 (Mucientes, 
Valladolid, negro grano fino, gris amarronado grano medio, marrón grano grueso).

\section{Las materias trabajadas}

Son todas las materias manipuladas mediante utensilios líticos por el hombre prehistórico, como piel, hueso, asta, madera o conchas. La mayoria de ellas no han llegado hasta nuestros dias, puesto que se trata de materias orgánicas que han ido desapareciendo. Así, sólo tenemos constancia de su utilización a través de las huellas de uso.

En la actualidad se ha experimentado con un alto número de ellas con el fin de registrar el tipo de huellas que deja cada una. A través de la técnica de bajos aumentos se identifica la dureza relativa de las materias, divididas éstas en duras, semiduras, blandas y semiblandas (Odell et alii. 1980). Desde los trabajos de Keeley (1980) con el microscopio metalográfico se puede identificar en gran medida la materia trabajada de forma más específica y no sólo su dureza relativa.

Cada materia no presenta la misma homogeneidad de huellas según el tipo específico que se trabaje, así la madera es una de las más variables, en relación a la dureza y estructura propia de cada especie (Plisson, 1985). En otras como el hueso, la carne o la piel, procedentes de especies distintas, no se han observado diferencias (Keeley, 1980; Anderson, 1981).

Las materias presentan una dureza caracteristica que influye en su resistencia al trabajo. Ésta. a su vez, determina el grado de penetracićn del borde activo en la materia trabajada regulando la fricción y, por tanto, el desarrollo y área de expansion de las huellas (Keeley, 1980).

Junto al tipo de materia trabajada se considera el estado de humedad en que se encuentra. Los estados son fresco, seco, húmedo -es decir, remojado despues de seco-, quemado y hervido.

Se ha argumentado que la presencia de humedad favorece el desarrollo del pulimento (Anderson, 1981), pero hemos comprobado que únicamente sucede asi en aquellos casos en que la humedad potencia la fricción entre la materia y el borde activo, y que, por el contrario, el exceso de humedad en materias porosas frena el desarrollo de esta huella al limitar la fricción.

En nuestros experimentos hemos trabajado con las siguientes materias: asta, hueso, diente, madera, vegetales, tierra, piel (sola, con abra- 
sivos, con pelo), cuero, carne (sola, con piel, con hueso), tendón, pez (con y sin espina), concha y piedra. Las especies han sido: ciervo, cabra. vaca, conejo, cerdo, sarda, chicharro, bígaros, vieiras, pino, roble, sicomoro, helechos, gramineas salvajes, arenisca, caliza, pizarra y ocres.

\section{La acción}

Hemos definido como acción el conjunto de gestos mecánicos que se ejecutan en una labor concreta como serrar madera, cortar piel o cepillar hueso. Por actividad entendemos el conjunto de acciones que componen una producción más amplia y tienen una finalidad más compleja, por ejemplo, la elaboración de una azagaya o el proceso de trabajo de la piel para la realización de vestidos o bolsas.

Durante el planteamiento de nuestro programa experimental optamos por realizar acciones ejecutadas mecánicamente, manteniendo fijas todas las variables de cada acción. Nuestro objetivo era tratar de identificar las variables a través de las huellas, como único modo de reconstruir la acción. La forma más correcta de plantear las acciones consiste en la elección de las variables que las determinan y no de las acciones a priori. Cada conjunción específica de variables forma una acción concreta. Las variables están jerarquizadas según su propio sentido y se estructuran en un esquema arboriforme. Las variables son las siguientes:

\section{Generales:}

- Conformación de la zona activa. Número de planos que forman la zona activa: lineal o poliedro.

- Ángulo del borde. El que forma el diedro en la zona activa: recto, medio, agudo.

- Forma de aplicación de la fuerza. Sistemas de relación entre la fuerza, el útil y la materia trabajada, que se expresa en el tipo de contacto, continuo o discontinuo, y la aplicación de la fuerza, instantánea o prolongada: presión, percusión directa y percusión indirecta.

- Ángulo de trabajo. El formado por la bisectriz del ángulo del filo y la materia trabajada: perpendicular y oblicuo. 


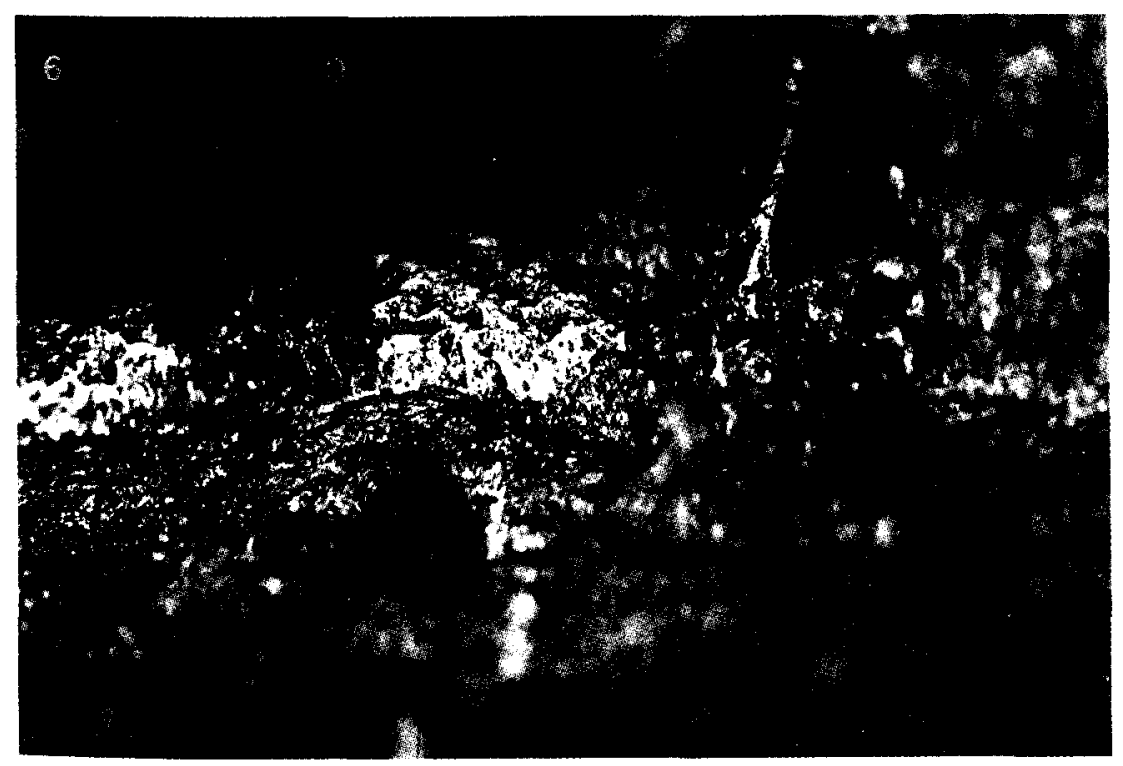

I.ám. I,A. Trabajo de madera tresca. Pulimento (200 X).

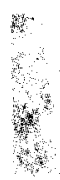

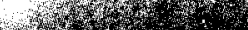
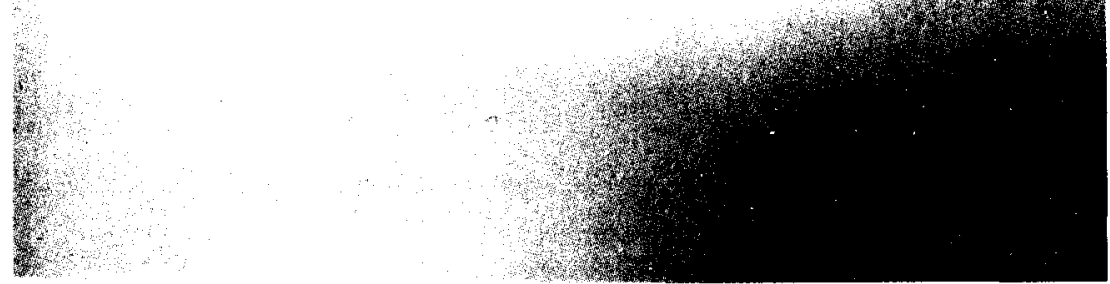

Lám. I,B. Trabajo de asta humeda. Pulimento (200 X). 
Variables de acciones de presión:

- Desplazamiento en el espacio. Forma en que la masa del útil cambia de lugar dentro del mismo plano: direccional y rotatorio.

- Tipo de dirección. Posición del borde respecto a la dirección del movimiento: longitudinal y transversal.

- Sentido del trabajo. Modo de apreciar la dirección desde un punto a otro: uno y dos sentidos.

Variables de acciones de percusión:

- Direccionalidad. Número de direcciones que intervienen en el trabajo: unidireccional y bidireccional.

Otros conceptos, comunes en todas las acciones, que se han tenido en cuenta son el de la cara en contacto (la que mantiene mayor proximidad con la materia trabajada), el de cara activa (la que va delante en el movimiento de la pieza) y cara pasiva (la que no es ni activa ni contacto, sólo se da en los poliedros).

A partir de la localización del borde activo, la identificación de la acción se realiza por etapas, desde la más generales como la forma de aplicación de fuerza hasta las más especificas, como la acción concreta.

Una vez que experimentalmente se compruebe la posibilidad de reconstruir la acción mediante la identificación de las variables, se deberán emprender experimentos más complejos realizados con acciones en las que las variables no se mantengan mecánicamente, sino que el útil se adapte a las características del trabajo o pueda realizar acciones diferentes dentro de una misma actividad. 
Esquema en árbol de las acciones

Bordes lineales $\quad\left[\begin{array}{l}\text { presión } \\ \text { percusion }\end{array} \quad\right.$ Bordes poliedros $\quad\left[\begin{array}{l}\text { buril } \\ \text { triedro }\end{array}\right.$
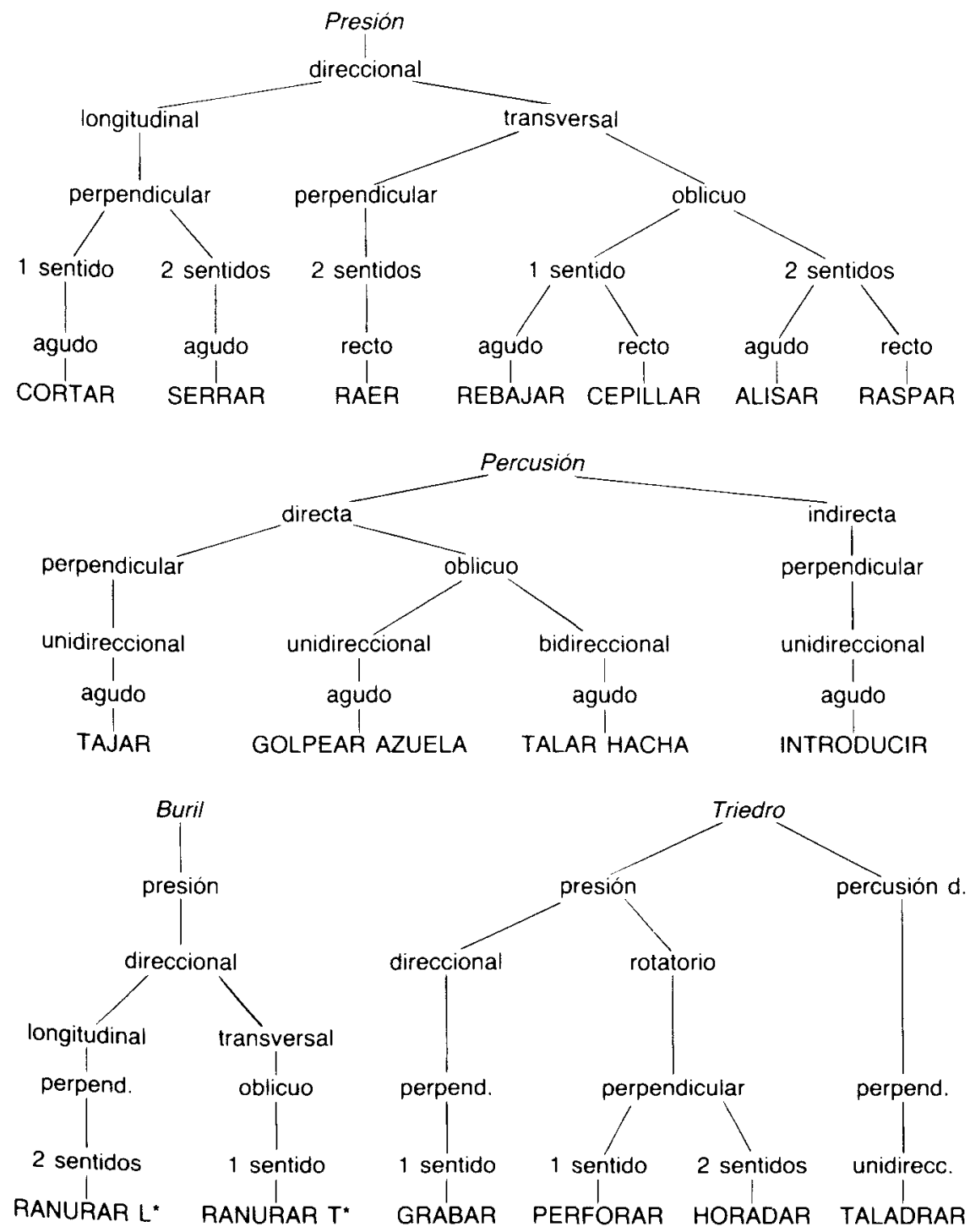

* Ranurar L y T equivalen a utilizar el diedro del buril en sentido longitudinal y transversal aunque dada la conformación de este borde las huellas se reflejan en todas las caras. La acción de grabar no utiliza el buril en su conjunto sino únicamente uno de los triedros que lo forman, o cualquier tipo de borde poliedro con terminación en ápice. 


\section{El tiempo}

Esta variable se ha tomado como medida de referencia del desarrollo de las huellas respecto a otras variables como las materia prima y la materia trabajada.

Su cómputo debe ser registrado a intervalos regulares en el conjunto experimental y no de forma aleatoria dado que carecería de valor como medida de comparación. Los tiempos que elegimos en nuestro experimentos fueron $3,7,15$ y 30 minutos, y más adelante los ampliamos a 7 , 15,30 y 60 minutos. En algunos casos hemos registrado tiempos diferentes porque algunos bordes se volvieron inutilizables en el transcurso del experimento, bien al romperse en acciones de percusión o en el trabajo sobre materias duras, bien al embotarse debido a la presencia de grasa en los trabajos sobre piel y carne.

Ocres y abrasivos

Abrasivos son los elementos que desgastan una materia por frotamiento. En las labores preshitóricas pudieron ser utilizados de manera intencional, como los ocres y colorantes, o bien su presencia fue accidental, así el polvo, la tierra, la arena o las esquirlas que saltan del borde durante el trabajo. En opinión de Semenov (1964), estos abrasivos accidentales son propios de las condiciones primitivas de trabajo.

El ocre es una materia frecuente en el registro arqueológico. Etnográficamente se ha constatado que se emplea de forma abundante por sus poderes antisépticos e impermeabilizantes, en especial en el tratamiento de pieles (Adouin y Plisson, 1982).

Todos estos elementos actúan como agentes abrasivos y provocan la formación de estrías (Semenov, 1964). Además la presencia masiva de ocre, tierra o arena incrementa el desarrollo del pulimento y embota el borde activo, haciéndole perder eficacia.

Hemos utilizado ocre molido y tierra en el trabajo de las pieles, con el propósito de ampliar nuestro registro experimental de huellas. Su empleo facilitó el trabajo sobre las zonas internas de la piel al impedir resbalar al útil. 


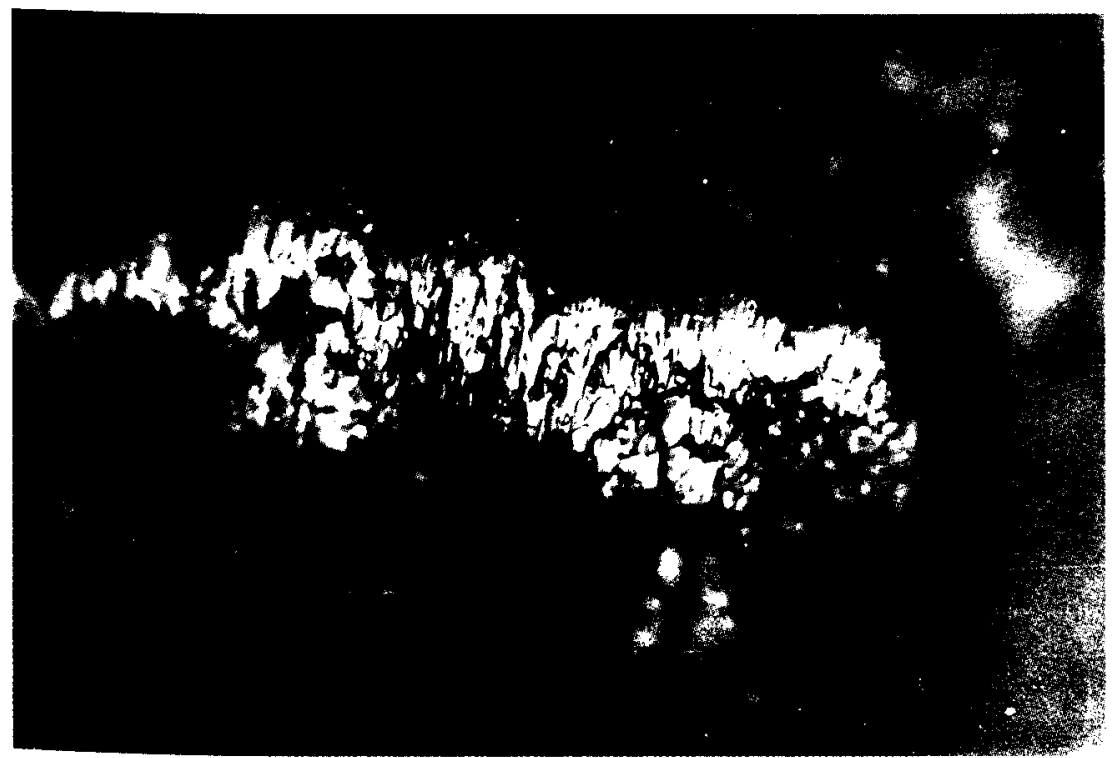

Lam. I,C. Trabajo de hueso. Pulimento y embotamiento (200 X) fresco.

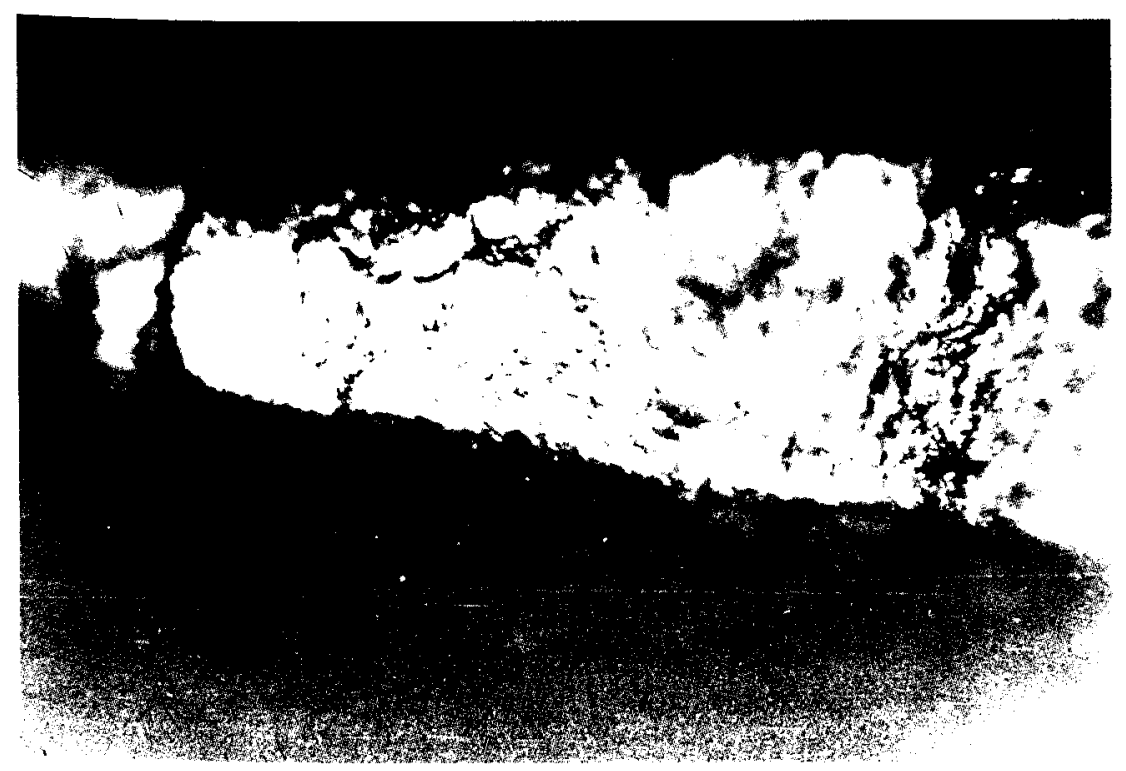

Lam. II,A. Pulimento sobre faceta de buril. Trabajo de piel fresca (200 X). 


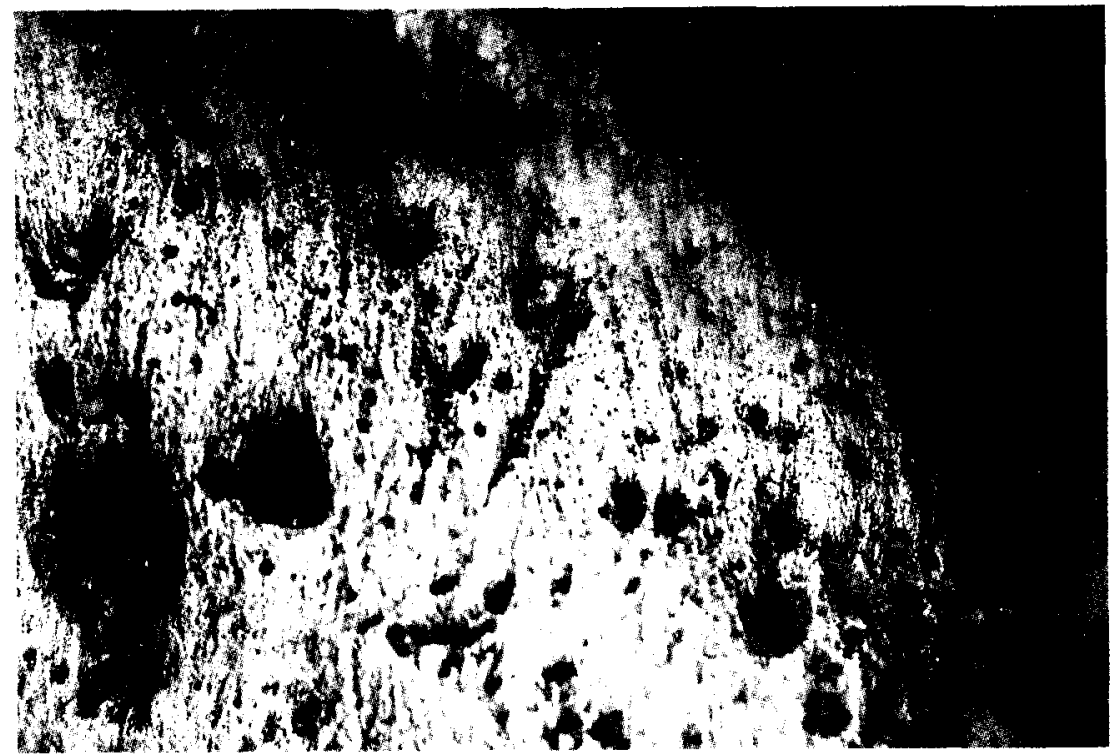

Lam. II.B. Aspecto del pulimento producido por el trabajo de piel fresca con abrasivos (ocre) (100 X).

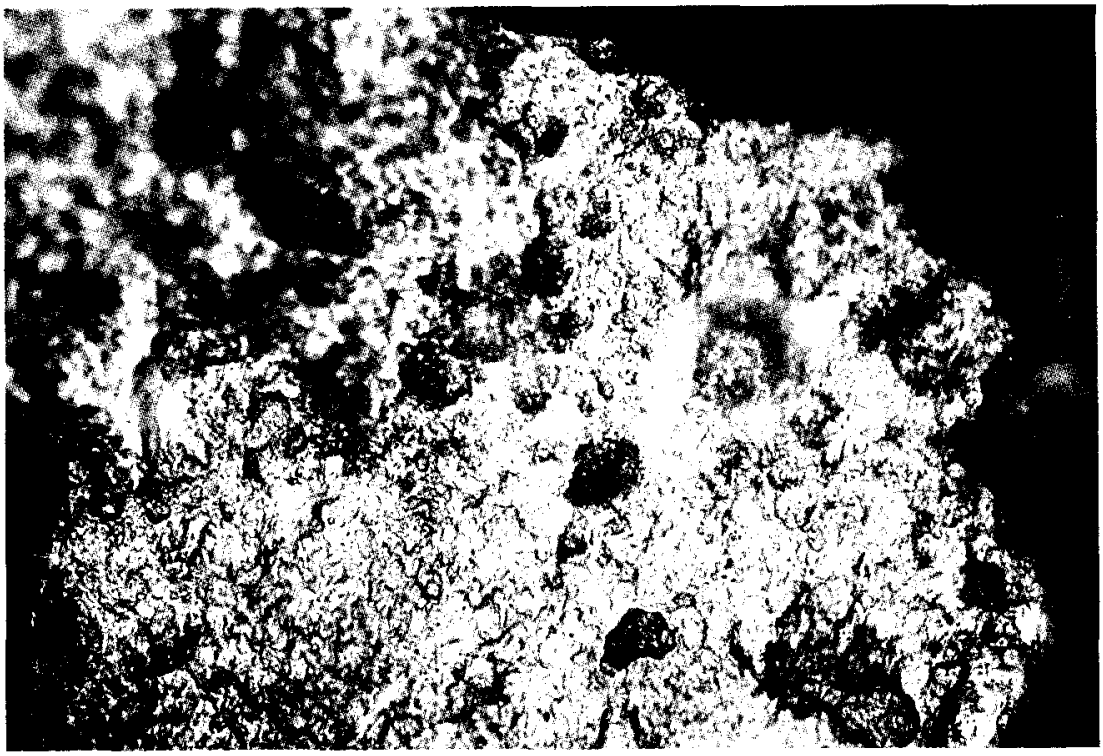

Lam. II,C. Trabajo de la tierra. Pulimento y estaria en cinta entre dos macroagujeros $(200 \mathrm{X})$. 
Enmangues y formas de prensión

La forma de prensión de las piezas es un aspecto que especifica las condiciones de uso y facilita su comprensión. Las piezas pueden utilizarse enmangadas en materias como asta, hueso o madera, sujetas directamente con la mano o utilizando alguna materia blanda como la piel como elemento protector.

Los enmangues han sido clasificados según permitan el roce con el útil o no. En el primer caso las huellas dejadas por la fricción con el mango aparecen más desarrolladas, en el segundo son difusas y pueden ser confundidas con alteraciones propias de la materia prima o incluso no llegar a formarse (Moss, 1983).

La mayor parte de nuestros experimentos han sido realizados sujetando el útil con la mano, bien con ella desnuda, bien con guante de piel. En unos pocos experimentos de persecución con hachas y azuelas hemos empleado mangos de madera donde se fijaron las piezas con tiras de cuero ensebado. No hemos apreciado huellas debidas a enmangues. Las huellas dejadas por la presión directa de la mano son poco frecuentes y pueden llegar a enmascararse en el material arqueológico debido a la presencia de pátinas y lustre del suelo.

\section{VARIABLES DEPENDIENTES}

Son los fenómenos que se desean explicar en relación a las condiciones elegidas, las huellas de uso. Éstas son el pulimento, el embotamiento, las estrías y los desconchados. No hemos incluido un estudio de residuos dado que su identificación requiere un conocimiento muy especializado y una observación con microscopio electrónico de barrido que no nos ha sido posible llevar a cabo.

Cada tipo de huella se caracteriza por un conjunto de atributos que la reflejan y están en relación con la conformación específica de las variables independientes.

\section{El pulimento}

Es una alteración de la microtopografía del silex que refleja la luz de forma diferente a la de la superficie fresca de esta materia. Keeley (1980) 
lo caracteriza por los siguientes atributos: cantidad de luz reflejada (luminosidad/opacidad), aspecto de su superficie o textura (rugosidad/tersura) y presencia de accidentes típicos (agujeros, ondas...).

Para este autor, cada materia trabajada produce un pulimento que estando bien desarrollado es típico de esa materia. Distingue asi los pulimentos de plantas, madera, hueso, asta trabajada longitudinal y transversalmente, conchas, piel fresca, húmeda y seca y carne. Posteriormente se han añadido los de pescado, tierra y piedra, bien por uso, bien debidos a las labores de talla y retoque.

El proceso de formación del pulimento ha sido uno de los temas más discutidos dentro de la Escuela de los altos aumentos. Los primeros trabajos apoyaron la hipótesis de formación del pulimento debido a la abrasión entre el borde activo y la materia trabajada (Crabtree, 1974; Dauvois, 1977; Diamond, 1979, Kamminga, 1979; Masson, 1981, 1982; Unger-Hamilton, 1984; Yamada, en prensa).

Seguidamente, Whitthoft (1967) explicó la formación del lustre de cereal, que no es sino un pulimento vegetal muy desarrollado, mediante un proceso de fusión. En él el calor engendrado en el trabajo diluye la silice del borde y ésta, al solidificarse, constituye el pulimento.

Anderson (1981) y Mansur (1983) han reelaborado la hipótesis de Whitthoft para explicar la formación de todos los pulimentos mediante un proceso de disolución de la sílice del borde durante el uso.

Otro problema en debate respecto a estas huellas es la identidad entre la materia trabajada y el pulimento que genera. La identidad, expresada de forma contundente por Keeley, y, en general, por la mayoría de los analistas de altos aumentos, ha sido puesto en tela de juicio más recientemente. Las críticas pueden resumirse en el comentario de Levi Sala (1988) en el que destaca la coincidencia de aspectos entre pulimentos producidos por materias diversas, al tiempo que la misma materia puede producir diferentes tipos de pulimento.

La identificación de la acción mediante el pulimento se apoya principalmente en la situación de esta huelia sobre las caras del borde activo.

\section{Embotamiento}

Denominamos asi al redondeamiento producido en el borde por efecto del uso; dentro del borde afecta al filo, a las zonas altas internas de la microtopografía como las aristas y al contorno de los desconchados. 


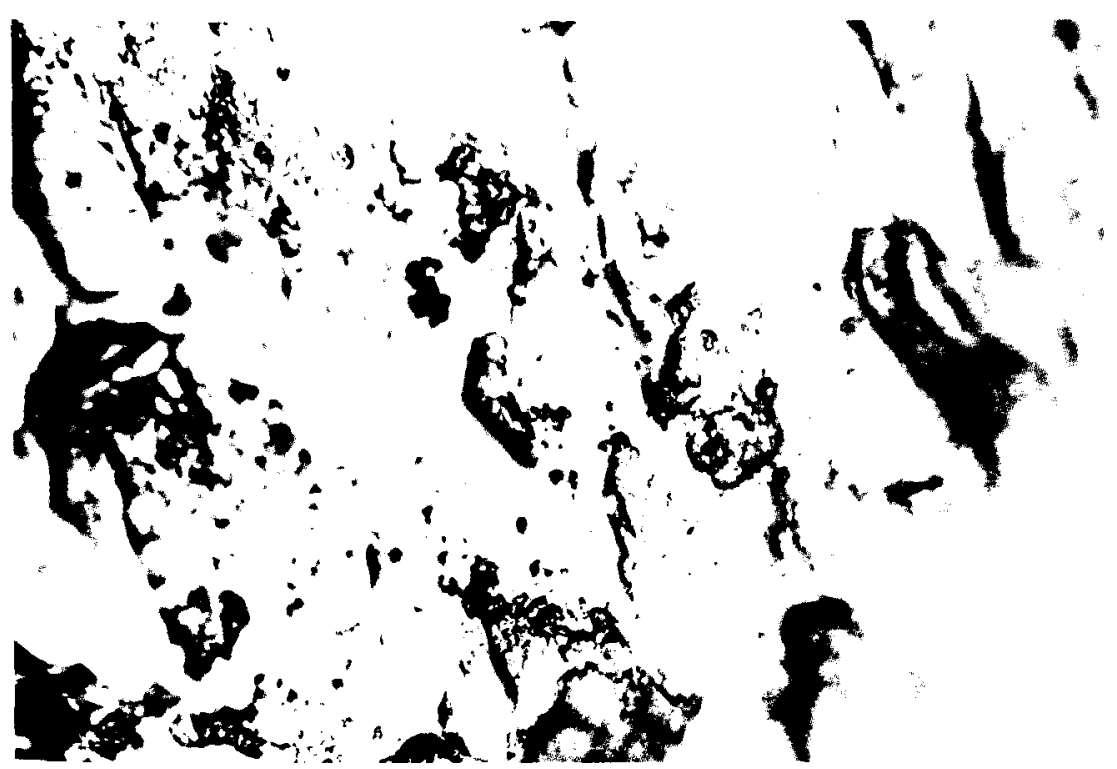

Lam. III,A. Pulimento y estria de fondo rugoso, trabajo de plantas (200 X)

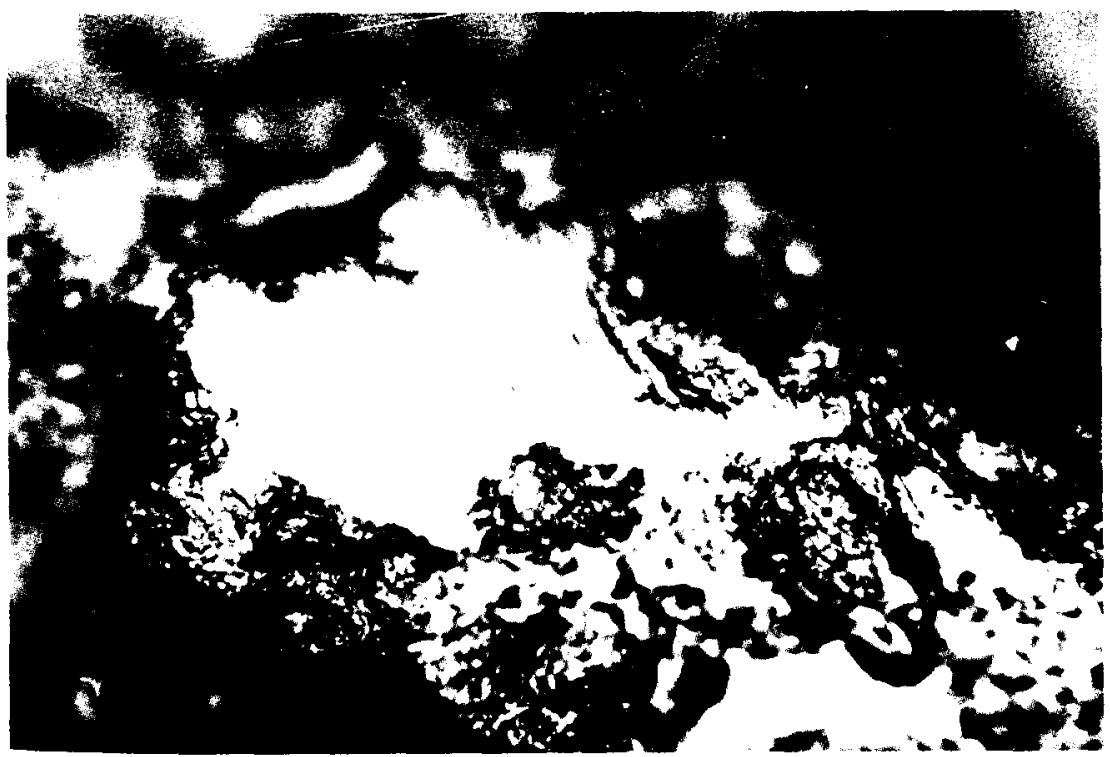

Lam. III,B. Trabajo de caliza humeda. Pulimento y estrias oblicuas de fondo rugoso $(200 X)$. 
Puede ser producido también por efectos de la sedimentación o debido a la manufactura del útil (Anderson, 1981), por lo que su presencia en las colecciones arqueológicas debe de ser tomada con cautela y siempre en relación con el resto de las huellas.

Aunque esta huella se ha asociado tradicionalmente con el trabajo de la piel (Keeley, 1980), sobre todo si se le añaden abrasivos (Mansur, 1983), y de la piedra (Grace, 1989), en mayor o menor medida es común a la mayoría de materias y acciones. Su importancia en la identificación de la acción radica en la posición que ocupe sobre las caras del borde activo.

\section{Estrias}

Son trazos lineares, excavados en surco o adiciones de pulimento, que siguen la dirección mantenida durante el uso por el filo activo.

Según Semenov (1964) son los rasgos más indicativos del movimiento de la pieza. Las observa a bajos aumentos pero no las describe ni sistematiza. La abundancia de estrias en los materiales rusos estudia-

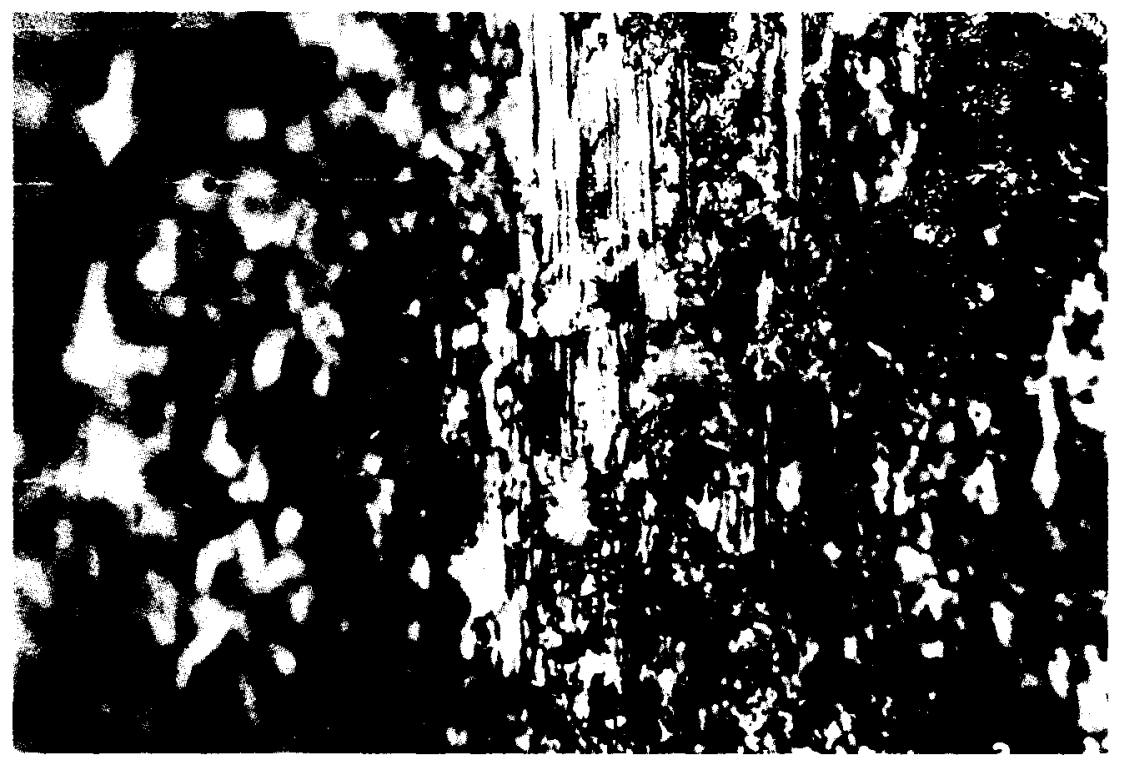

Lám. III,C. Trabajo de caliza humeda. Estrias de percusion (200 X). 
dos por Semenov, y claramente observables en las fotografías de sus publicaciones, ha sido achacada a la presencia de loess de las grandes llanuras, que actuaria de agente abrasivo provocando la abundancia de esta huella (Moss, 1983). Entre los materiales líticos estudiados en occidente las estrías son muy poco frecuentes e imposibles de ver a lupa binocular, únicamente son detectadas a partir de $200 \mathrm{X}$ en el microscopio metalográfico.

Para Keeley (1980) las estrías son las huellas más útiles para identificar el movimiento pero apenas son significativas, para diagnosticar las materias trabajadas. Las distingue por su origen en tres grupos: las formadas por efectos de la percusión, las debidas a causas accidentales durante la sedimentación como choques y rodamientos cuya distribución por la pieza es caótica y, finalmente, las originadas durante el uso, a las que sólo tiene en cuenta cuando van acompañadas de pulimento. Elabora una clasificación muy somera de ellas basada en su anchura y profundidad; entre sus tipos únicamente las denominadas estrías colmatadas se relacionan directamente con una materia, los vegetales.

Ha sido Mansur (1981) la autora que, hasta el momento, ha investigado con más profundidad este tipo de huella. A partir de la hipótesis de la génesis del pulimento por disolución explica que si durante el uso la superficie del sílex se convierte en gel de sílice, las estrías se originarán por la tracción de abrasivos sobre esta superficie y sus tipos dependerán del grado de disolución que haya alcanzado el gel. Así, un gel sólido se dará durante el trabajo de la piel, la carne y el hueso, en los primeros momentos de trabajo de la madera y los vegetales y durante la formación de estrías accidentales debidas a causas naturales. Una superficie con gel más fluido corresponderá al trabajo de las plantas, la piel con abrasivos y los efectos de la percusión. Los agentes abrasivos son granos de arena y polvo introducidos accidentalmente, microlascas saltadas del borde durante el uso, sobre todo en el caso de las materias duras como el hueso y elementos abrasivos utilizados intencionalmente como el ocre.

Sus tipos básicos son cuatro y se diversifican en función de su morfología, anchura y profundidad. De los cuatro tipos principales: estrías de fondo rugoso, de fondo liso, aditivas y colmatadas, las colmatadas son pulimento dispuesto linealmente, el resto son surcos excavados en la superficie del pulimento, caso de las debidas al uso, o silícea, si son formadas por causas accidentales. En cuanto a su frecuencia observa que son muy abundantes en el trabajo del hueso, relativamente abundantes en el del asta y la madera y escasas en el de la carne y la piel sin abrasivos. 
Como huellas diagnósticas del movimiento del borde activo son muy útiles, su único inconveniente es su escasez; Anderson (1981) sólo las observó en un tercio de su colección experimental y en la mitad de la colección arqueológica. Como indicadoras de la materia trabajada, y salvo el caso de las estrías colmatadas asociadas al trabajo de los vegetales, tan sólo Mansur las considera relativamente significativas.

\section{Desconchados}

Son los negativos de las microlascas saltadas del borde durante el uso. Su consideración como huella diagnóstica o no del uso ha levantado una de las más largas polémicas de los estudios funcionales. Junto al embotamiento es la única huella que puede ser observada a bajos aumentos, lo que lógicamente incrementa su valor para los seguidores de esta escuela. Desde los altos aumentos únicamente Akoshima (1979) apoya su importancia.

En los trabajos de Tringham y su grupo de la Universidad de Harvard (1974), se establecieron las relaciones entre los desconchados y el uso, relaciones apoyadas por todos los seguidores de los bajos aumentos y reafirmadas por Akoshima. En ellas los desconchados de uso se distinguen con relativa facilidad de los debidos a causas accidentales y al retoque; son indicativos del movimiento según su distribución en el borde, asi son bifaciales en las acciones longitudinales como serrar y unifaciales en las transversales como raspar. Respecto a la materia trabajada se establecen a partir de atributos como la morfologia, distribución y cantidad, pero no diferencian la materia trabajada especifica sino su dureza relativa.

Los analistas de altos aumentos han refutado todas estas conclusiones (Keeley, 1980; Anderson, 1981; Moss, 1981; Vaughan, 1981; Mansur, 1983...). Sus argumentos son los siguientes:

- Es prácticamente imposible diferenciar los desconchados de uso o de retoque en el mismo borde, lo que impide el análisis de esta huella en los filos retocados. En la misma medida resulta confuso distinguir los debidos al uso de los provocados por causas accidentales como choque o pisoteo. Por nuestra parte apuntamos que aunque experimentalmente se pueda establecer el valor diagnóstico de los desconchados, y sólo de forma muy general, no sucede igual con las piezas arqueológicas, ya que 
desconocemos las causas reales que los han provocado, y estas causas son más difíciles de discriminar en los desconchados que en el resto de las huellas.

- No siempre aparecen después del uso y cuando lo hacen a menudo no son bifaciales en las acciones longitudinales ni unifaciales en las transversales. En nuestra opinión en este hecho además se establece una correlación falsa, señalada también por Grace (1989). No es el tipo de dirección que lleva el útil el factor que influye en la distribución de las huellas sobre cada cara del borde, sino el ángulo de trabajo que mantiene el borde con la materia trabajada. Asi, a las acciones con ángulo alto les correspondería una distribución bifacial de todas las huellas y a las de ángulo bajo unifacial. Si tal correlación se ha mantenido desde las dos escuelas se debe al hecho de que las acciones longitudinales (cortar y serrar) se realizan con ángulo de trabajo alto y la mayoria de las transversales (raspar, rebajar, cepillar...) con ángulo bajo.

- En general se concluye que el valor diagnóstico de los desconchados es escaso debido a que existen numerosas variables que influyen en su formación y se da una gran convergencia de formas entre tipos de origen distinto. Después de un amplio estudio sobre esta huella Vaughan (1985) concluye que «los resultados experimentales o bien contradijeron las afirmaciones establecidas sobre patrones de microdesconchados o revelaron sólo tendencias generales donde otros habian establecido reglas definidas".

Aunque los estudios funcionales basados únicamente en los desconchados han caído en desuso, una buena parte de los analistas los incluyen en su observación puesto que son útiles, como tendencia, para sugerir la dureza relativa del material trabajado o poner en evidencia algunas materias o acciones concretas a partir de atributos muy especificos.

\section{LIMPIEZA, MEDIOS DE OBSERVACIÓN Y FORMAS DE REGISTRO}

La limpieza elimina los residuos adheridos al borde y, por tanto, facilita la observación microscópica. Es frecuente que después de la experimentación queden pegados al borde restos, generalmente orgánicos, de la materia trabajada, al tiempo que en las piezas arqueológicas se aprecia parte del sedimento mineral que las envuelve. Para eliminar los resi- 
duos experimentales es preciso utilizar disolventes inorgánicos mientras que los minerales requieren el empleo de ácidos. Es importante, entonces, mantener idéntico tratamiento para ambas colecciones incluyendo ácidos y disolventes inorgánicos en las dos para evitar que se produzcan variaciones debidas a la limpieza (Keeley, 1980).

Aunque los productos más utilizados son el ácido clorhídrico, $\mathrm{ClH}$, y los hidróxidos de sodio y potasio, $\mathrm{NaOH}, \mathrm{KOH}$, este tratamiento ha sido criticado a menudo por los efectos secundarios que puede provocar en las piezas, principalmente en la apariencia del pulimento. Como alternativas se han realizado baños en jabón neutro o detergente biológico (Levi-Sala, 1988) o en acetona ( $D^{\prime} E$ Errico, 1986). Un tratamiento intermedio puede hacerse con agua oxigenada, $\mathrm{H}_{2} \mathrm{O}_{2}$, seguido de ácido acético $\left(\mathrm{CH}_{3} \mathrm{CO}_{2}\right)_{20}$ que es el que hemos seguido nosotros junto con detergente amoniacal en cubeta ultrasónica. En realidad, los efectos secundarios se observan después de un tratamiento muy largo, incluso de semanas y meses, y los baños cortos no afectan al pulimento (Moss, 1985). Además se hace preciso una limpieza rigurosa con el fin de asegurar la calidad de la observación microscópica, aunque es conveniente un primer examen de las piezas arqueológicas con el fin de determinar y registrar la existencia de restos como ocre o resinas que la limpieza pudiera eliminar.

Como medios de observación de pulimentos, estrías y embotamiento hemos utilizado un microscopio petrográfico Olympus BHT con oculares de $10 \mathrm{X}$ y objetivos de $5 \mathrm{X}, 10 \mathrm{X}, 20 \mathrm{X}, 50 \mathrm{X}$ y $80 \mathrm{X}$. El rango más empleado fue el de $200 \times$ quedando los inferiores para visiones de conjunto y los superiores para detalles más concretos. Utilizamos también un filtro azul que mejoró notablemente la observación. Para el registro de desconchados y dibujo de los bordes empleamos un estereomicroscopio Olympus SZH con cámara clara e iluminación exterior de fibra de vidrio. Está equipado con oculares de $10 \mathrm{X}$ y $20 \mathrm{X}$ y dos objetivos intercambiables de $0,5 \mathrm{X}$ y $2 \mathrm{X}$. El rango con el que se realizó la observación y el dibujo fue de $10 \mathrm{X}$. La fotografía fue tomada con una cámara Olympus OM-2n con tapa impresora y acoplada al microscopio y al estereomicroscopio por un tubo adaptador. Empleamos Plus $X$ de 150 Asa y Panatomic para las películas en papel y Ektachrome 160 o Agfa Dia Direct de 32 Asa para las diapositivas.

El registro de las huellas se ha llevado a cabo en cuatro tipos de ficha, superando el modelo que propusimos anteriormente (Gutierrez Sáez, 1986). En la general, una ficha por pieza, además del dibujo, los datos tecnológicos y condiciones de la experimentación se apuntaron los datos referentes al embotamiento. La ficha del pulimento se registró por cada borde activo de la pieza y las de desconchados y estrías se llevaron 
por caras del borde activo. Los datos fueron introducidos en un ordenador con un programa de base de datos y en cada ficha del programa se han registro individualmente todas las caras de cada borde activo.

\section{ANÁLISIS}

Durante la experimentación se trabajaron 433 piezas talladas por nosotros mismos. Los experimentos estuvieron determinados en parte por la facilidad que dan algunas materias para permitir observaciones más completas, en este sentido se aumentó deliberadamente el trabajo de la madera con el fin de ampliar el campo de análisis de las acciones. En el mismo sentido se redujo el número de piezas experimentales en aquellas materias que, como carne, tierra o vegetales, presentan una gama más corta de posibilidades de trabajo. Este hecho desequilibra, a su vez, el número de acciones a ejecutar a favor de las que trabajan materiales más duros (cuadro I).

El análisis de los datos consistió en la contrastación de las variables independientes con los atributos de las huellas de uso generadas; los atributos se seleccionaron en función de las hipótesis previas planteadas acerca del comportamiento esperado de cada variable independiente (cuadro II). Los grupos de variables establecidos fueron:

Para la acción: forma de aplicación de fuerza, tipo de dirección, ángulo del trabajo (presión), sentido del trabajo, ángulo del borde, tipo de repercusión, ángulo del trabajo (percusión directa), direccionalidad, bordes poliedros en buril y en ápice.

Para la materia trabajada: análisis general de los atributos que expresan el desarrollo de las huellas en todas las materias. Análisis cualitativo por estados de humedad y especies de las siguientes materias: asta, hueso, diente, madera, plantas, piel con y sin abrasivos, cuero, carne, carne con hueso y con piel, tendón, pez con y sin espina, concha, piedra y tierra.

También se analizaron los atributos de las huellas en relación con las materias primas empleadas y los diferentes tiempos de trabajo. 
CUADRO 1. RELACIÓN DE PIEZAS EXPERIMENTALES Número de piezas trabajadas en cada materia y estado

\begin{tabular}{|c|c|c|c|c|c|c|}
\hline & FRESCO & HERVIDO & HÚMEDO & QUEMADO & SECO & TOTAL \\
\hline Asta .. & - & - & 52 & - & 7 & 59 \\
\hline Carne $\ldots . . . \ldots \ldots . .$. & 4 & 1 & - & - & 1 & 6 \\
\hline Carne/hueso ......... & 8 & - & - & - & 一 & 8 \\
\hline Carne/piel .......... & 6 & - & - & - & - & 6 \\
\hline Concha ............ & - & 3 & - & - & 4 & 7 \\
\hline Cuero ........ & - & - & - & - & 3 & 3 \\
\hline$\ldots \ldots \ldots \ldots \ldots$ & 5 & - & - & 一 & - & 5 \\
\hline Hueso ........ & 55 & 4 & - & 7 & 7 & 73 \\
\hline Madera......$\ldots \ldots$ & 104 & - & 14 & 2 & 19 & 139 \\
\hline Pez ............... & 7 & - & - & - & - & 7 \\
\hline Pez/espina & 7 & - & - & - & 一 & 7 \\
\hline Piedra ............ & - & - & - & - & 16 & 16 \\
\hline Piel $\ldots \ldots \ldots \ldots \ldots$ & 22 & - & 17 & - & 25 & 64 \\
\hline Piel/abrasivo ........ & 7 & - & - & - & 4 & 11 \\
\hline Piel/pelo ............ & 2 & - & - & - & 4 & 6 \\
\hline Tendón $\ldots \ldots \ldots \ldots \ldots$ & 3 & - & - & - & 1 & 4 \\
\hline Tierra ............... & - & - & - & - & 4 & 4 \\
\hline Vegetal ............. & 7 & - & - & - & 1 & 8 \\
\hline TOTAL & 237 & 8 & 83 & 9 & 96 & 433 \\
\hline
\end{tabular}

Número de piezas trabajadas en cada acción y zona activa

\begin{tabular}{|c|c|c|c|c|}
\hline & BUR:L & LINEAL & TRIEDRO & TOTAL \\
\hline$\ldots \ldots \ldots \ldots \ldots \ldots \ldots$ & - & 20 & - & 20 \\
\hline Cepillar & - & 73 & - & 73 \\
\hline Cortar .... & - & 54 & - & 54 \\
\hline Golpear A ........ & - & 9 & - & 9 \\
\hline Grabar $\ldots \ldots \ldots \ldots \ldots \ldots \ldots \ldots \ldots \ldots$ & - & - & 30 & 30 \\
\hline 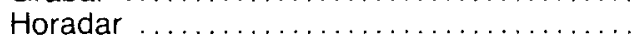 & - & - & 27 & 27 \\
\hline Introducir $\ldots \ldots \ldots \ldots \ldots \ldots \ldots \ldots \ldots \ldots$ & - & 12 & - & 12 \\
\hline Perforar. & - & - & 45 & 45 \\
\hline Raer ...... & - & 7 & - & 7 \\
\hline Ranurar $L \ldots \ldots \ldots \ldots \ldots \ldots \ldots \ldots$ & 7 & - & - & 7 \\
\hline Ranurar $T \ldots \ldots \ldots \ldots \ldots \ldots \ldots \ldots \ldots \ldots$ & 5 & - & - & 5 \\
\hline - & - & 6 & - & 6 \\
\hline Rebajar & - & 53 & - & 53 \\
\hline Serrar .... & - & 61 & - & 61 \\
\hline Tajar ............................ & - & 5 & - & 5 \\
\hline Taladrar $\ldots \ldots \ldots \ldots \ldots \ldots \ldots \ldots \ldots \ldots$ & - & - & 5 & 5 \\
\hline Talar $\mathrm{H} \ldots \ldots \ldots \ldots \ldots \ldots \ldots \ldots \ldots . \ldots \ldots$ & - & 14 & - & 14 \\
\hline$\ldots \ldots \ldots \ldots \ldots \ldots \ldots \ldots \ldots \ldots \ldots$ & 12 & 314 & 107 & 433 \\
\hline
\end{tabular}


Introducción a las huellas de uso: los resultados de la experimentación

CUADRO II. APARECEN SENALADOS CON ASTERISCO LOS ATRIBUTOS DE LAS HUELLAS DE USO (EN HORIZONTAL) SELECCIONADOS EN EL TRATAMIENTO DE DATOS PARA SU CONTRASTACION CON LAS VARIABLES INDEPENDIENTES (EN VERTICAL).

ANALLISIS

\begin{tabular}{|c|c|c|c|c|c|c|c|c|c|c|c|}
\hline & $\begin{array}{l}\text { M. TRA. } \\
\text { BAJADA }\end{array}$ & ESTADO & $\begin{array}{l}\text { MAT } \\
\text { PRIMA }\end{array}$ & $\begin{array}{l}\text { TEXTU. } \\
\text { RA. }\end{array}$ & TIEMPO & $\begin{array}{l}\text { FA } \\
\text { FUERZA }\end{array}$ & DESPLA- & $\begin{array}{l}\text { T DI. } \\
\text { RECCION S }\end{array}$ & SENTIDO & $\begin{array}{l}\text { A. TRA- } \\
\text { BAJO }\end{array}$ & $\begin{array}{l}\text { A. } B O R- \\
\mathrm{DE}\end{array}$ \\
\hline \multicolumn{12}{|l|}{ PULIMENTO } \\
\hline 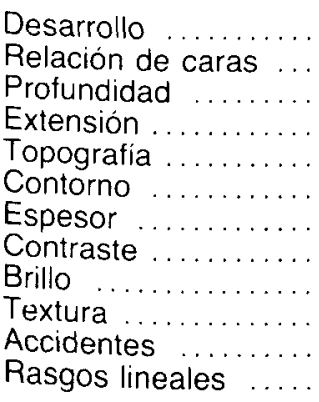 & $\begin{array}{l}. \\
. \\
. \\
. \\
. \\
. \\
. \\
.\end{array}$ & $\begin{array}{l}\star \\
\star \\
\star \\
\star\end{array}$ & * & * & * & $\begin{array}{l}\text { * } \\
\text { * } \\
\text { * } \\
\text { * } \\
\text { * } \\
\text { * } \\
\text { * }\end{array}$ & * & $\begin{array}{l}* \\
* \\
* \\
* \\
*\end{array}$ & $\begin{array}{l}* \\
* \\
* \\
*\end{array}$ & $\begin{array}{l}\text { * } \\
\text { * } \\
\text { * } \\
\text { * }\end{array}$ & $\begin{array}{l}\text { * } \\
* \\
*\end{array}$ \\
\hline \multicolumn{12}{|l|}{ EMBOTAMIENTO } \\
\hline $\begin{array}{l}\text { En el filo ........... } \\
\text { Relación de caras ... }\end{array}$ & . & * & * & * & * & * & * & * & * & * & * \\
\hline \multicolumn{12}{|l|}{ ESTRİAS } \\
\hline 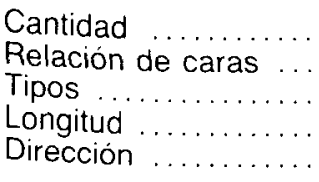 & . & $\begin{array}{l}\star \\
\star \\
\star\end{array}$ & * & * & * & $\begin{array}{l}\star \\
\star \\
\star \\
\star \\
\star\end{array}$ & $\begin{array}{l}* \\
\star \\
\star \\
\star\end{array}$ & $\begin{array}{l}\star \\
\star \\
\star \\
\star\end{array}$ & $\star$ & * & * \\
\hline \multicolumn{12}{|l|}{ DESCONCHADOS } \\
\hline 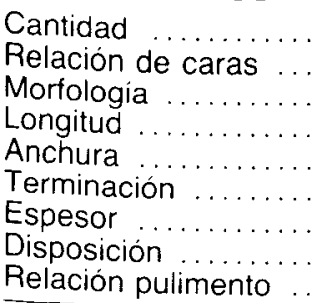 & $\begin{array}{l}. \\
. \\
. \\
. \\
. \\
.\end{array}$ & $\begin{array}{l}\text { ^ } \\
\star \\
\star \\
\star \\
\star \\
\star\end{array}$ & * & * & * & $\begin{array}{l}* \\
* \\
* \\
* \\
* \\
* \\
\text { * } \\
\text { * } \\
\text { * }\end{array}$ & $\begin{array}{l}\text { * } \\
* \\
\text { * } \\
\text { * } \\
\text { * } \\
\text { * } \\
\text { * }\end{array}$ & $\begin{array}{l}\text { * } \\
\text { * } \\
\text { * } \\
\text { * } \\
\text { * } \\
\text { * } \\
\text { * } \\
\text { * }\end{array}$ & $\begin{array}{l}* \\
\star \\
* \\
* \\
*\end{array}$ & * & $\begin{array}{l}* \\
\star \\
* \\
*\end{array}$ \\
\hline
\end{tabular}

* Textura se refiere a la granulometría, concepto este último mal aplicado por los analistas de huellas de uso. 


\section{INTERPRETACIÓN O RECONSTRUCCIÓN}

Los resultados obtenidos en el análisis de las variables no pueden calificarse de homogéneos. El motivo reside en las peculiaridades propias de cada variable, tanto en las que constituyen la función -la materias primas y trabajadas, el tiempo y la acción-como en las huellas de uso.

\section{Las huellas de uso}

Los atributos analizados muestran que no todas las huellas ofrecen el mismo grado de fiabilidad para la reconstrucción de la función. De los cuatro tipos en estudio los desconchados y el embotamiento son las huellas que menor identidad presentan con los fenómenos que las han provocado. Este hecho debe de llevarnos a tratar las conclusiones de su estudio en colecciones arqueológicas con especial cautela, puesto que además en estos dos tipos de huella es más difícil decidir si la causa de su formación es el uso o bien la talla o fenómenos accidentales ocurridos en la sedimentación. El pulimento y las estrías, por su parte, aunque no han reflejado una identidad absoluta con las variables independientes que las conforman sí mantienen una relación más estrecha con ellas y se constituyen en las huellas más diagnósticas de la materia trabajada y la acción, especialmente el pulimento, ya que las estrías tienen una presencia muy baja que además puede calificarse de aleatoria. Se ha confirmado la correspondencia del pulimento con la materia trabajada y de las estrías con la acción, mantenida por el conjunto de analistas de altos aumentos, pero también hemos comprobado que determinadas variables de la acción se ven reflejadas en atributos específicos del pulimento, así como que cada grupo de materias trabajadas tiene tendencia a producir determinados tipos de estrías, al menos cuantitativamente.

El diagnóstico funcional debe de apoyarse en la observación de los cuatro tipos de huellas; es el análisis posterior el que discriminará el valor de cada una de ellas en la interpretación.

\section{La acción}

El trabajo ha mostrado que es posible discernir la mayor parte de variables que conforman las acciones en el conjunto de huellas generadas, ya que prácticamente todas ellas ofrecen el comportamiento esperado. En nuestra opinión se debe a que habiamos establecido una defi- 
nición precisa de las variables lo que, a su vez, nos permitió plantear las hipótesis de su comportamiento con relativa exactitud.

Al organizar la conformación de las acciones según un esquema arboriforme, la identificación tuvo que seguir forzosamente el mismo esquema, desde las variables más generales a las más específicas. Los atributos más significativos han resultado ser: la cantidad de cada tipo de huella y su extensión en la forma de aplicación de fuerza, la dirección de las estrías y de los componentes lineales del pulimento en el tipo de movimiento y la posición e intensidad de las huellas sobre cada cara del borde activo en el ángulo de trabajo. Más difícil ha resultado ser la identificación del sentido del trabajo en la presión y de su equivalente, la direccionalidad, en la percusión, ya que dependen de la precisión con que se reconstruyan las variables anteriores. En el ángulo del borde es sintomático el grado de destrucción de la silueta, que depende también estrechamente de la dureza de la materia trabajada, pero esta variable nos la da el propio borde activo. Cuando las huellas están medianamente desarrolladas es bastante probable la identificación de los rasgos generales del movimiento y según la línea del esquema a seguir de la acción realizada.

\section{La materia trabajada y la materia prima}

En ambas materias su relación con las huellas de uso se ha mostrado menos estrecha; aunque los resultados han puesto de manifiesto la diversidad de comportamientos de cada tipo en estudio estamos lejos de comprender los motivos. No partíamos, como en la acción, de un conocimiento intrínseco de las variables, por lo que difícilmente podiamos plantear unas hipótesis razonables de su comportamiento. De las materias trabajadas desconocemos su composición específica y en la materia prima los análisis nos han mostrado que no existe relación entre sus componentes y la variabilidad de huellas que presentan por tipos. Dado que el uso implica un hecho mecánico, la fricción de dos materias, deberemos de conocer aspectos más específicos de ambas, como la textura, el grado de dureza y la estructura de sus elementos para comprender el proceso que se produce.

En las materias trabajadas los resultados nos llevan más a hacer una identificación por grupos de materias que por materias individuales. Tenemos las tendencias pero faltan aún por limitar los rasgos diagnósticos específicos de cada materia. Los grupos formados son: 
- Grupo vegetal: incluye la madera y las plantas no leñosas.

- Grupo de materias óseas: hueso, asta, diente y espina.

- Grupo de materias grasas: hueso, carne, piel, tendón, pez, tierra $y$ asta interna.

Las huellas de materias como la piedra y el molusco quedan apenas esbozadas por el carácter aleatorio de sus atributos, por lo que la experimentación deberá de ampliarse para establecer patrones más definidos.

Dentro de cada grupo no existen las mismas posibilidades de individualizar cada materia en el caso de un desarrollo medio de las huellas. Es relativamente fácil distinguir entre las del grupo vegetal, y dentro del de materias grasas entre la piel, la tierra y el trabajo interno del asta frente al resto; por el contrario, la identidad de caracteres de las huellas producidas por todas las materias óseas es bastante alta, por lo que la dificultad de distinción es mayor.

Los diferentes tipos de materias primas han mostrado un comportamiento diferente de las huellas en las mismas condiciones de trabajo, llegando en algunos casos a excluir toda posibilidad de identificación en algunos de ellos, lo que evidencia la importancia de esta variable en la formación de las huellas. La segunda conclusión que podemos extraer de este hecho es que la ausencia de huellas no siempre expresa la ausencia de trabajo, lo que lleva a complejizar aún más el fenómeno de la función.

\section{El tiempo}

El tiempo es la variable más impredecible en el diagnóstico funcional. El desarrollo de las huellas depende tanto de las materias prima y trabajada y de la intensidad del contacto como de la duración del trabajo, por lo que sus resultados se solapan con los del resto de las variables, tanto en piezas cuyas huellas aparezcan bien desarrolladas como en las que apenas se vean esbozadas.

\section{CONCLUSIONES}

- La traceología o estudio de las huellas de uso es la única técnica que nos conduce a la comprensión de la función del utillaje lítico y, a 
través de él, a la propia funcionalidad de los yacimientos, puesto que otro acercamiento a este tema carece de hipótesis demostrables. Su soporte principal es el método experimental a través del análisis de las variables implicadas: las independientes o condiciones de la experimentación y las dependientes o huellas de uso. Su medio más idóneo de observación es la microscopia de altos aumentos, principalmente con el microscopio petrográfico, que permite un examen riguroso del conjunto de las huellas.

- El desconocimiento de las propiedades físicas de dos de las variables independientes, las materias primas y trabajadas, ha impedido una aplicación total del método. Una experimentación más sistemática y el conocimiento de estas variables tendrá por resultado una mejor comprensión del proceso de formación de las huellas, y, por consiguiente, contribuirá a ampliar el diagnóstico funcional.

- La identificación de las huellas de uso es relativamente accesible respecto a la acción ejercida. En la materia trabajada tiende más hacia el reconocimiento de grupos de materias que de tipos especificos; no obstante, su posibilidad ha quedado patente mediante algunos de los tests-ciegos realizados hasta ahora. La proporción de identificaciones fiables es todavía baja; la investigación del conjunto de factores que generan las huellas podría contribuir a incrementarla.

- Su aplicación al material arqueológico se hace más compleja al añadirse los fenómenos provocados por los procesos de elaboración del útil y las alteraciones sufridas durante la sedimentación. Estas últimas precisan por sí mismas de un amplio cuerpo experimental cuyos resultados nos permitan una evaluación más rigurosa de sus efectos sobre las huellas de uso.

Hay que valorar como muy positivos los resultados obtenidos hasta el momento, teniendo en cuenta el corto espacio de tiempo en que ha desarrollado la moderna traceología. 


\section{BIBLIOGRAFÍA}
A.A.: American Antiquity.
B.A.R.: British Archaeological Reports.
B.S.P.F.: Bulletin de la Société Préhistorique Française.
C.N.R.S.: Centre Nationale de la Recherche Scientifique.
C.I.M.A.: Centro de Investigación y Museo de Altamira.
(N.) L.T.: (Newsletter of) Lithic Techonology.
S.P.B.: Studia Praehistorica Belgica.
T.M.O.: Travaux de la Maison de l'Orient.

Akoshima, K., (1978): “An experimental study of microflaking", Kokogaku Zasshi 66 (4), págs. 1-27.

- (1987): "Microflaking quantification", The human uses of flint and chert. G. de G. Sieveking, M. H. Newcomer (Eds.), págs. 71-80.

ANDERSON, P. C., (1980): “A testimony of prehistoric tasks: diagnostic residues on stone tool wotking edges", World Archaelogy, 12 (2), págs. 181-194.

Anderson-Gerfaud, P. C., (1981): Contribution méthodologique à l'analyse des micro-traces d'utilisation sur les outils préhistoriques. Thèse de $3^{\text {eme }}$ Cycle, núm. 1.607.

- (1982): "Comment préciser l'utilisation agricole des outils préhistoriques, Cahiers de l'Euphrate 3, págs. 149-164.

- (1988): Using prehistoric stone tools to harvest cultivated wild cereals: preliminary observations of traces and impact», B.A.R. 411, págs. 175-196.

Audouin, F.; Plisson, H., (1982): Les ocres et leurs témoins au Paléolithique en France: enquête et expériences sur leur validité archéolo- 
gique", Cahiers du Centre de Recherche Préhistorique de l'Université de Paris VI, 8, págs. 33-80.

BouCher DE PERTHES, J., (1847-1857): Antiquités celtiques et antédiluviennes. Mémoire sur l'industrie primitive et les arts à leur origine. Tomos I y II. París.

BORDES, F., (1965): “Utilisation possible des côtes des burins", Fundberichte aus Schwaben, Neue Folge 17, págs. 3-4.

- (1973): "Position des traces d'usure sur les grattoirs simples du Perigordien Supérieur évolué de Corbiac (Dordogne)", Estudios dedicados al Prof. don Luis Pericot, pág. 55-60.

BrezILLON, M., (1973): “L'outil préhistorique et le geste technique», L'Homme hier et aujourd'hui, págs. 123-132.

Bustillo M. A., (1983): "Minerales de la silice en ambiente sedimentario: estudio y aplicaciones", Industria Minera 230, págs. 27-33.

Cox, I., (1936): «The indian spoon», A.A. 1, págs. 317-320.

Crabtree, D., (1974): “Grinding and smoothig of stone artifacts», Tebiwa 17, págs. 1-6.

DauvoIs, M., (1977): "Stigmates d'usure présents par des outils de silex ayant travaillé l'os. Premiers résultats", Méthodologie apliquée à l'industrie de l'os préhistorique, págs. 275-292.

D'ERrico, F., (1987): "Technologie et fonction du burin de Ripabianca dans le cadre culturel du Néolithique ancien de I'Italie septentrionale", L'Anthropologie 91 (2), págs. 411-432.

DiAmond, G., (1979): "The nature of so-called polish surface on stone artifacts", Lithic use - wear analysis. B. Hayden (Ed.), págs. 156-166.

Evans, J., (1872): The ancient stone implements, weapons and ornaments of Great Britain. Longmans, Green, Reader and Dyer. Londres.

FLENNIKEN, J. J.; HAGgaRTY, J., (1979): “Trampling as an agency in the formation of edge damage: an experimental in lithic technology", Northwest Anthropological Research Notes 13, págs. 208-214.

Geneste J. M.; Plisson, H., (1986): «Le Solutreen de la grotte de Combe Sauniere 1 (Dordogne)", Gallia Préhistoire 29 (2), págs. 9-28.

Grace, R., (1989): Interpreting the Function of Stone Tools. The quantification and computerisation of microwear analysis, B.A.R. 497.

Grace, R.; Ataman, K.; Fabregas, R.; Haggren, C. M. B., (1988): «A multivariate approach to the functional analysis of stone tools, B.A.R. 411, págs. 217-230.

GutiérRez SAEZ, C., (1986): “Ficha para el estudio de huellas de uso sobre material lítico", Revista de Arqueologia 58, págs. 48-53.

- (1990): Huellas de uso: pautas de análisis experimental. Tesis Doctoral inédita. 
Gutiérrez Saez, C.; González Urquijo, J. E.; ibánezz Estévez, J. J., (1988): “Alteraciones microscópicas en el tratamiento convencional del material lítico: su incidencia en las huellas de uso", Munibe, Suplemento 6 , pág. 83-89.

Hammat, H., (1970): “A paleoindian butchering kir», A.A. 35, págs. 141. 152.

ibánez Estévez, J. J.; Gonzalez Urquijo, J. E.; Laguera Garcia, M. A.; GutiérRez SÁez, C., (1987): "Huellas microscópicas de talla", Kobie 16, pág. 151-161.

KAAMINGA, J., (1979): "The nature of use-polish and abrasive smoothing on stone tools", Lithic Use-Wear Analysis, B. Hayden (Ed.), págs. 143-157.

KantMan, S., (1970): “Esquisse d'un procédé analythique pour l'étude macrographique de encoches", Quaternaria 13, págs. 269-280.

KEELEY, L. H., (1974): "The methodology of microwear analysis: a comment on Nance", A.A. 39, págs. 120-128. ${ }^{\star \star \star}$ Keeley sobre desconchados.

- (1978) "Los usos de los instrumentos de silex en el paleolítico", Investigación y Ciencia 16, págs. 52-60.

- (1980): Experimental Determination of Stone Tool Uses: a Microwear Analysis. University of Chicago Press. Chicago.

KeELEY, L. H.; NewCOMER, M. H., (1977): “Microwear analysis of experimental flint tools: a test case», Journal of Archaelogical Science 4, págs. 29-62.

LENOIR, M., (1971): “Traces d'utilisation observees sur un nucleus à lamelles", B.S.P.F. 68, págs. 69-70.

LEVI-SALA, I., (1988): "Processes of polish formation on flint tool surface", B.A.R. 411, págs. 83-98.

LuBBock, J., (1872): Pre-Historic times, 3 ed., Williams and Norgate. Londres.

MANSUR, M. E., (1980): “Las estrías como microrrastros de utilización: clasificación y mecanismos de formación", Antropología y Paleontología Humana 2, págs. 21-41.

Mansur-Franchomme, M. E., (1983): Traces d'utilisation et technologie lithique: exemples de la Patagonie. Thèse de $3^{\text {eme }}$ cycle presentée à I'Universitè de Bordeaux I.

Masson, A., (1981): Petroarcheologie des roches siliceuses. Intérêt en Préhistoire. Thèse de $3^{\text {eme }}$ Cycle. Universite Claude Bernard. Lyon I.

- (1982): "Les pièces lustrèes des sources d'el Kown (Syrie)", Cahiers de I,prEuphrate 3, págs. 141-147. 
Moss, E. H., (1983): The functional analysis of flint implements: Pincevent and Pont d'Ambon: two cases studies from the french final Palaeolithic, B.A.R. 177.

Moss, E. H.; NewCOMER, M., (1982): «Reconstruction of stone tool use at Pincevent: microwear and experiments", Studia Praehistorica Belgica 2, págs. 289-312.

Moure Romanillo, A.; Gonzalez Morales, M. R., (1988): «El contexto del arte parietal. La tecnología de los artistas en la cueva de Tito Bustillo (Asturias)", Trabajos de Prehistoria 45, págs. 19-50.

Múleer, H., (1903): “Essais de taille de silex, montage et emploi des outils obtenus, LÁnthropologie 14, págs. 417-436.

NEWCOMER, M., (1980): "Savoir utiliser les outils préhistoriques", Dossiers de l'Archaeology 46, págs. 18-22.

Newcomer, M.; Grace, R.; Unger-Halmiton, R., (1986): "Investigating microwear polishes with blind-test", Journal of Archaeological Science 13 (3), págs. 203-218.

- (1987): "Microwear polishes, blind-test and texture analyses", The Human Uses of Flint and Chert. G. de G. Sieveking, M. H. Newcomer (Eds.), págs. 253-263.

Newcomer, M.; KeELEY, L. H., (1979): "Testing and method of microwear analysis with experimental flint tools", Lithic Use Wear Analysis, B. Hayden (Ed.), págs. 195-205.

ODELL, G. H.; ODELL-WEREECKEN, F., (1980): "Veriting the reliability of lithic use-wear assesments by "blind test": the low power approach", Journal of Field Archaelogy 7, págs. 87-120.

OVER, W. H., (1937): "The use of the thumb-scraper», A.A. 2, págs. 208209.

Plisson, H., (1982): "Une analyse fonctionelle des outillages basaltiques", S.P.B. 2, págs. 241-244.

- (1984/85/86): “Altérations des micropolis d'usage: quelques expériences", Early Man News 9/10/11, págs. 111-116.

- (1985): Étude fonctionelle d'outillages lithiques préhistoriques par l'analyse des micro-usures: recherche méthodologique et archéologique. Thèse de $3^{\text {erne }}$ Cycle. Université de París, Panthéon-Sorbonne. París.

Pradel, L., (1973): «Traces d'usage sur les burins du Paléolithique Supérieur", B.S.P.F. 70, págs. 26-31.

Prat, F.; Sonneville-Bordes, D., (1969): “Découverte récente du Paléolithique supérieur à la grotte de Font de Gaume (Dordogne)", Quaternaria 11, págs. 115-132.

RAY, C. N., (1937): "Probables uses of the flint end-scrapers", A.A. 2, págs. 303-306. 
Rosenfeld, A., (1971): "The examination of use marks on some magdalenians end-scrapers", The British Museum Quaterly 35, págs. 176182.

SEITZER, D. J. (1977): «Form, us, function: microwear analysis and its applications to Upper Paleolithic burins", Papers of the Archaeological Institute. New Series 2, págs. 5-20.

Semenov, S. A. (1964): Prehistoric technology. An experimental study of the oldest tools and artifacts from traces of manufacture and wear. Cory, Adams and Mackay Ltd., Londres. Traducción española 1981, Akal.

SHEA, J. J., (1988): «Metodological considerations affecting the choice of analytical techniques in lithic use-wear analysis: test, results and applications», B.A.R. 411, págs. 65-82.

SCHIFFER, M. B., (1976): Behavioral Archeology. Academic Press. Nueva York.

SONNENFELD, D. J., (1962): "Interpreting the function of primitive implementes", A.A. 28 , págs. 56-65.

Spurrel, F., (1892); "Notes on early sickles", Archaeological Journal, 49, págs. 53-59.

SUSSMAN, C., (1985): «Microwear on quartz: fact or fiction?", World Archaelogy 17 (2), págs. 101-111.

Tringham, R.; Cooper, G.; Odell, G. H.; Vortek, B.; Whitman, A., (1974): «Experimentation in the formation of edge-damage: a new approach to lithic analysis", Journal of field Archaeology 1, págs. 171-196.

UNGER-HAMILTON, R., (1984): "The formation of use-wear polish of flint: Beyond the "deposit versus abrasion". Controversy", Journal of Archaeological Science 11, págs. 91-98.

Unrath, G.; Owen, L. R.; Van Gijn, A.; Moss, E. H.; Plisson, H.; VaugHAN, P. C., (1984/85/86): "An evaluation of microwear studies: a multi-analist approach", Early Man News 9/10/11, págs. 117-176.

VAN GiJN, A., (1984/85/86): "Fish polish, fact and fiction", Early Man News 9/10/11, págs. 13-28.

VAUGHAN, P. C., (1981): Lithic microwear experimentation and the functional analysis of a Lower Magdalenian stone tools assemblage. Ph. D. Dissertarion. University of Pennsylvania.

- P. C., (1985): Use-wear analysis of flaked stone tools. The University of Arizona Press.

WALKER, P., (1978): "Butchering and stone tool function", A.A. 43 (4), págs. $710-715$.

WHITTOFT, J., (1967): "Glazed polish on flint tools», A.A. 32, págs. 383388. 
WYLIE, H. G., (1975): “Artifact processing and storage procedures: a note of caution", N.L.T. 4 (1-2), págs. 17-19.

YAMADA, S., (en prensa): The formation process of use-wear polishes. Department of Archaeology. University of Tohoku, Sendai. 